\title{
Students as learners through the eyes of their teachers in Rwandan higher education
}

\author{
Penelope Mbabazi, Lars Owe Dahlgren and Andreas Fejes
}

\section{Linköping University Post Print}

N.B.: When citing this work, cite the original article.

This is an electronic version of an article published in:

Penelope Mbabazi, Lars Owe Dahlgren and Andreas Fejes, Students as learners through the eyes of their teachers in Rwandan higher education, 2012, International Journal of Lifelong Education, (31), 4, 503-521.

International Journal of Lifelong Education is available online at informaworld ${ }^{\mathrm{TM}}$ :

http://dx.doi.org/10.1080/02601370.2012.689377

Copyright: Taylor \& Francis (Routledge)

http://www.routledge.com/

Postprint available at: Linköping University Electronic Press

http://urn.kb.se/resolve?urn=urn:nbn:se:liu:diva-76553 


\title{
Students as learners through the eyes of their teachers in Rwandan higher education
}

Penelope Bamwesiga Mbabazi, Lars Owe Dahlgren, Andreas Fejes

Linköping University, Sweden

International Journal of Lifelong Education, 31(4), 503-521.

\begin{abstract}
In this study, we aim to explore and thematically analyze the higher education teachers' notions about most important problems related to students' learning, including the teachers' notions of the approaches to learning that the students adopt The study was carried out in Rwanda, Central Africa, with 25 university teachers engaged in group interviews. Inspired by the concepts of metaphors for learning and approaches to learning, five main categories of students' learning problems were identified: Dependence, Physical and economic resources, experience of a deep approach to learning, reading culture, and previous preparation for higher education. These problems are interrelated and point to the need to understand study levels in education systems as being interdependent. The teaching and learning process of one level influences the quality of learning of the other level. A difference/gap in learning approaches between levels of education greatly impacts difficulty in students' learning and understanding especially when they shift from a lower level to another. Understanding educational levels as closely linked is thus of great importance for enhancing quality in learning in higher education in Rwanda.
\end{abstract}

Keywords: student learning; approaches to learning; quality in learning; higher education in Rwanda

\section{Introduction}

The focus of this study is on describing and analysing teachers' notions about the most important problems when it comes to students' learning and the way they approach learning. The interest in acquiring a deeper understanding of learning in higher education is attributable to the argument that economic development will not be achieved without a knowledge-based society. Materu (2007) argues that a knowledge-based society will not make sense if higher learning institutions do not offer quality education that meets acceptable local and international standards and according to (Woldetensea 2008), quality education will not make sense if learning does not enable learners to develop knowledge and skills that satisfy the rapidly changing labour market demands. Materu (2007) further highlights the fact that the major problems of African education are not, as most think, universality; rather, it is quality that is the problem, and the responsibility for quality of higher education ultimately rests with the Higher Education Institutions (H.E.Is). Higher education is deemed important to national economic growth and for nations and individuals to prosper and be able to cope with challenges; as such, the demand for higher education in Africa has increased phenomenally (Openjuru 2011). One of the possible interpretations is the current emphasis on an increased demand for quality of students' learning. Learning should be individualized, localized, and globalized, while teaching is regarded as a process for initiating, facilitating and sustaining students' self-learning, self-exploration and self-actualization as well as multiple intelligence and multiple thinking (Cheng and Ching 2007). This kind of concern inspires us to reflect on the intangible domains of quality teaching and learning in higher education, and the importance of higher education generally speaking.

This article takes Rwanda as a case study. Rwanda is now at a crossroads of its development. The Rwandan government has embarked on transforming its economy from an agricultural-based economy into a knowledge-driven economy. However, Rwanda, like many African countries, one effective direction is to steer higher education, with a greater quality assurance focus (Woldetensea 2008). According to Rwanda Education Sector Strategic Plan (ESSP) 2008-2012 (2008), Higher Learning Institutions (H.L.Is) in Rwanda need to revise their curricula in order to match the changing needs of the 
society and the global economy. For example, there is evidence from studies undertaken in 2009, that the quality of Post Basic Education (PBE) graduates is not adequate to serve the economy's needs and that this was a shortcoming in all sectors (MINEDUC-ESSP 2010:26).

Additionally, according to the study by Mashishi and Rabin (1999), it is suggested that if educators aim to develop the kind of people that will be able to cope with the demands of the business world, educators need to utilize research on student learning at the tertiary level to improve their own teaching and the quality of students' learning. Biggs (2001) points out that assuring and enhancing the quality of teaching and learning in universities is still a major concern and, according to Abrandt Dahlgren and Dahlgren (2002), the quest for a better way of learning and teaching in higher education is a challenge that continues to intrigue educators and suggests that an attempt should be made to shift to a perspective that gives priority to students' learning. Rwanda's ambitions as regards future economic development call for a system of higher education that is aligned with the contemporary trends in the area, such as the shift towards student-centred forms of teaching and the ambition to bridge the gap between higher education and working life. A requirement for such changes is an understanding of the nature of the prevailing culture of learning and knowledge. Hence, it is very important that students and teachers share a common view of knowledge as well as learning. This is the main rationale for carrying out the study reported in this article. Students must also develop generic skills required by the labour market. Put differently, higher education is expected to enable students to develop abilities that can be exploited and utilized in new conditions that involve flexibility, communication skills, computer skills and teamwork. This takes us beyond the present debate to the views of Bowden \& Marton (1998), who see the institution of higher education as a university of learning rather than a university of teaching or a university of research. Sooner or later, those individuals who do not have the skills, competence, knowledge and qualifications needed to function in the knowledge society will find themselves on the wrong side of the knowledge and learning divide (Wurzburg 2005).

\section{Aims of the study}

The main aim of this study is to describe and analyse teachers' notions about most important problems related to students' learning, including the teachers' notions of the approaches to learning that the students adopt. In order to achieve this aim and enable the formulation of a framework, it is imperative to listen to teachers and explore their notions. Teachers are significant actors in the students' life, and hence one would expect them to have significant experience of students' learning and their approaches to learning. Empirical data were gathered through focus group interviews and the core question was formulated as: What are the most important problems when it comes to students' learning and the way they approach learning?

\section{Theoretical frames of reference}

The theoretical framework has been scoped to cover two basic elements: metaphors for learning and approaches to learning. The focus will be on what the literature has to say about understanding learning by emphasizing a set of contemporary metaphors of learning and basic approaches to learning that may be linked to these metaphors. This framework will subsequently be used for a deeper understanding of what the teachers have to say about their students' ways of understanding and setting about learning. The knowledge we have today of students' learning in higher education has been generated through empirical studies where students have been the informants (e.g Marton and Säljö 1984, Mashishi and Rabin 1999, Biggs 2001, Entwistle et al. 2001, Ramsden 2003, Rodriguez and Cano 2006, Chen et al. 2007, Dahlgren et al. 2009). There is, however, a shortage of studies where teachers have been asked to give their views on student learning, especially in relation to African universities. This particular study introduces a new dimension to the research on student learning by investigating the different main problems students are assumed to face, when they are engaged with their learning and the ways they go about their learning, from the teachers' perspective. 


\section{Basic metaphors for learning}

By concentrating on the basic metaphors for learning, we hope to be able to elicit some of the fundamental assumptions underlying both learning and our practice as students and as teachers. The current discourse on learning finds educational research caught between two basic metaphors. One is the acquisition metaphor and the other is called the participation metaphor. The struggle is about trying to shift from traditional learning, which aligns with the acquisition metaphor, to more contemporary notions of studies dominated by the participation metaphor. The acquisition metaphor for learning, in the words of Sfard (1998), conceives of human learning as an acquisition of something, the act of gaining knowledge whereby the basic units of knowledge can be accumulated, gradually refined, and combined to form ever richer cognitive structures. In contrast, the participation metaphor is based on the contemporary view of learning that focuses on the evolving bonds between the individual and others, giving prominence to the aspect of mutuality characteristics of part-whole relationships and thus making salient the dialectic nature of the learning interaction rather than the individual mind.

The learning process entails transmission, grasp, reception, internalisation, acquisition, accumulation, etc., while learning during participation mirrors togetherness, solidarity, and collaboration, and hence promotes an interest in people in action. Among the indicators of change are such expressions as learning in the community, cooperative learning, communication, reflective discourse and collective reflection, democratic competence. One gets the impression that the learner becomes an integral part of the team, interested in participation in certain kinds of activities rather than in accumulating private possessions. However, Sfard (1998) and Lave and Wenger (1991) issue a warning about promoting just one of the metaphors and claim that learning is after all a kind of interplay between individual experiences and reflection and participation in social contexts. Contemporary research views learning as legitimate peripheral participation or as an apprenticeship in thinking. Rogoff (1990) proposes the idea of apprenticeship participation, referring to the system of values that guides the newcomer to a community of practice, the relationship between the nature of the activity involved and the institutions of the community in which it occurs. When it comes to understanding learning and developing ways to approach learning tasks in a well-organized manner, students in higher education would benefit from having teachers who are good role models.

\section{Approaches to learning}

The fundamental concept of approaches to learning was coined in the 1970s (e.g. Marton and Säljö 1976). There are two well-known contrasting approaches, named deep and surface approaches to learning. Based on a number of studies, deep learning may be described as the capacity to critically examining new facts and ideas, incorporating them in existing cognitive structures and making numerous links between ideas. This eventually leads to understanding and long-term retention of ideas so that they can be used for problem solving in unfamiliar contexts. Surface learning, on the other hand (Marton and Säljö 1984, Entwistle et al. 2001, Ramsden 2003), is defined as accepting new facts and ideas uncritically and attempting to store them as isolated, unconnected items, which does not promote understanding or long-term retention of knowledge and information. Important to our understanding are the aspects of 'what' and 'how' that are always merged together during learning. The 'what' aspect concerns the meaning of a learning task, while the 'how' aspect concerns the structure of a learning task and depending on how the two aspects have been merged, one can talk either of a deep-holistic approach or a surface-atomistic approach employed by students (Ramsden 2003). The practice of deep learning or surface learning may be influenced by various factors, especially the learning environment, teaching approaches, conception of knowledge and learning and assessment methods, all of which are shared by the teacher and the student (cf. Prosser and Trigwell 1999, Biggs 2001, Abrandt Dahlgren et al. 2007, Dahlgren et al. 2009). Based on the above knowledge, it is worth mentioning that every learning situation should include the potential for application (of something learned previously), and every situation of application implies the potential for learning (something new).

Ramsden, (2003) presents three qualitatively different levels in learning. The most abstract level comprises thinking critically and imaginatively, and being able to communicate effectively; at the second 
level, there are more specific, content-related changes in understanding linked to specific disciplines or professions. Finally, there are highly categorical proficiencies such as knowledge of factual information, technical and manipulative skills, and specific problem-solving techniques. Knowledge at all these levels, and the ability to connect knowledge between the levels is regarded as essential if graduating students are to be considered educated people. Related to this, Bowden and Marton (1998) suggest that learners need to acquire rich experiences in their learning since the ability to deal with varying situations in the future by discerning their critical features and focusing on them simultaneously originates from past experiences. By developing familiarity with ways of being, ways of thinking and ways of seeing the world through the eyes of students at a university in central Africa, learners will develop skills and knowledge needed to solve problems which are impossible to define in advance (Bowden and Marton 1998). This implies that university education should inspire and enable individuals to develop their capabilities to the highest potential levels throughout life, so that they grow intellectually, are wellequipped to work, can contribute effectively to society and achieve personal fulfilment (Ramsden 2003).

\section{Higher education in Rwanda}

According to the Rwanda National Qualification Framework (RNQF), higher education comprises of learning institutions that provide further general or technological training programmes compared to those provided by secondary school education' (OGRR 2006:22). The higher education subsector is currently undergoing vigorous transitional reforms and these reforms are closely linked to the global forces that greatly influence the country's development agenda, mainly aimed at carving a niche in the knowledgebased society and to compete effectively in the global economy (MINEDUC-ESSP 2010). As Rwanda strives for acceptability and integration in a wider community, both regional and international and as higher education tries to reform, the aim is to have citizens access quality education and thus enable the citizens to join the competition in the world of work. In order to achieve such aims, the HEC came up with a National Qualification Framework (RNQF) for Higher Education and the associated code of practice, that spelt out the standards meant to support the H.L.Is in providing appropriate learning programmes that are internationally credible; aiming at transforming the quality of higher education to be rather fit for purpose (HEC-RNQF 2007:2). HEC defines quality as 'fit for purpose', meaning that education provision enables the students to achieve the intended learning outcomes and these are normally designed to the needs of Rwanda. H.L.Is have the responsibility to publically demonstrate that they are sensitive to national needs as well as demonstrating that the education and training they are providing are of standards such that the qualifications are recognised nationally, regionally and internationally.

Since 2008, there has been implementation of Bologna modular system in teaching and learning practices in all higher learning institutions. The shift to Bologna, modular system was an initiative to improve the quality of students learning through emphasising learner-centred approach rather than the teacher-centred approach that monopolised the education system previously; as well as to address the challenges of limited transferability of students from one institution to another, failure to permit multiple entries and exits for students, difficulties in programme comparability of different institutions that characterised the previous education system (MINEDUC-HEC, 2007). The Executive Director of HEC explains,

There was much to gain in terms of quality assurance for graduates if universities adopt the modular system as opposed to the traditional way of teaching; we have been using the teacher centred type of teaching where the lecturer provides the students with everything hence giving the student no chance to do their own research. But this new system will allow participatory learning for the students. It allows the component of several teachers delivering various sections of the module, which helps in quality assurance due to the more detailed nature of subjects (Kwizera 2010).

Higher education strives, among other things, to ensure that teaching and learning are based on explicit learning outcomes, which are consistent with programme aims, and methods used are innovative and 
varied as regards the stated learning outcomes. An aim of the teaching approaches is to encourage independent learning with critical thinking and students take responsibility for their own learning. This being a new change in the teaching system, teachers have been required to take into account the needs of all categories of students, as pedagogical expectations will be translated into action through interaction between the teachers and the students (Mugisha 2010). According to HEC (2010), learning could be enriched by means of appropriate reference to cross-curricular links, current research, industrial applications and the development of generic skills such as communication and teamwork, and feedback could regularly be obtained from students and employers, and analysed and acted upon as appropriate.

Today according to the MINEDUC-ESSP 2010-2015 (2010), the major challenge is ensuring quality and equality in education, improving teaching and learning and the quality of provision so graduates have the requisite catalytic skills. Some studies have shown concern about academic preparedness, that graduates from higher education lack competence and lifelong learning skills needed for them to be successful in the world of work (ESSP 2010:26). The Rwandan minister of education and the executive director of HEC notes that the issue of poor quality of graduates has often been raised; the higher education provided has weak linkages to the labour market with low employability of its graduates and incompatibility with employers' needs (Kwizera 2010, 2011, ESSP 2010:26). This may be attributed to the urgent call to address the issue of quality in teaching and learning in higher education, especially with the continuously increasing competition for employability skills on the global market (ESSP 2010:26).

Referring to previous studies it is important to know about how students approach and orchestrate their learning, and what beliefs they hold about knowledge and learning, as away forward to enhance teaching and learning (Rodriguez and Cano 2006). This study relates to such ambition and that is why we have chosen to look at important problems related to students' learning and how they approach learning. It is assumed that in order to improve this kind of practice, you need to understand the problems student face in their learning and their approaches to learning.

\section{Methodological considerations \\ Design and data collection}

In order to get a variety of understandings about the important problems related to students' learning and how they approach their learning, a variety of teachers were engaged. This study targeted teachers, assuming that teachers are at the forefront of teaching and learning and are significant actors in the students' life (Chen et al. 2007) and are thus regarded as having important views about students' learning and their approaches to learning. A focus group technique was employed as a means of capitalising on group interaction to facilitate the collection of rich responses to the questions posed; group members, under the leadership of moderators were engaged collectively in giving reactions to the subject of discussion; in this case, the problems related to students' learning (Patton 2002). All participants have a similar background as university teachers and are from the same institution. This was facilitated eliciting a collective perspective, encouraging interaction between participants. Participants could provide checks and balances on each other and this facilitated minimising false and extreme views, thus promoting the quality of data (Krueger and Casey 2000). In total, there were five focus group interviews, and the size of the group was limited to five in order to allow participants to contribute actively. According to Patton (2002:385), focus group interviews consist of small groups of approximately six to ten people with similar backgrounds participating in the interview conducted to obtain a variety of perspectives. The other unique advantage was that with such limited numbers of participants in the focus groups, it was possible to quickly assess the extent to which there is a relatively consistent shared view or a large diversity of views (Patton 2002). Indeed, there were hardly any significant differences between the participants' comments. It must also be acknowledged that the focus groups, like all forms of data collection, also have limitations and must be approached tentatively. The most significant challenges for this study were, first, the difficulty in capturing non-verbal interactions (Patton 2002) since researchers may have less control over the direction of the discussion than in a one to one interview. Second, large 
groups may preclude everyone from having a chance to contribute (Patton 2002). These challenges were addressed by the moderators taking written notes while the focus groups were being interviewed and linking non-verbal interaction to the verbal accounts. The direction and control of the discussion was facilitated by the researchers preparing a questioning route with prompts prior to the interview and having moderators to manage the discussion. The size of the group was limited to allow all participants to contribute.

Data collection took place in conjunction with a workshop on teaching and learning in higher education organised at the National University of Rwanda. Participating teachers were informed of a research project about student learning in progress and were invited to participate in interviews. One of the researchers explained the nature and purpose of the study and it was made clear to the participants that the researchers would maintain the confidentiality of participants by using codes so as not reveal their identity. Twenty-five teachers volunteered to participate in the interviews and were asked to stay behind after the workshop for the data collection interviews. Of the twenty-five participants, five were from Education, five from Economics and Management, four from Medicine, four from Agriculture, six from Arts and Humanities, and one from the faculty of sciences. The twenty-five teachers were randomly divided into five focus groups (GI, G2, G3, G4, G5) and five moderators were randomly allocated to the five groups; each group consisted of five teachers and one $\mathrm{PhD}$ candidate as a moderator. The reason for mixing groups was in line with the aim of focus groups, which is to have a variety of opinions about the phenomenon discussed. Accordingly, the aim was to have a variety rather than comparison of faculties. Two main questions were asked and discussed by the groups: the first one concerned important problems when it comes to students' learning while the second concerned students' ways of setting about learning. The moderators participated in taking notes while the group interactions about the question posed were in progress. Each group discussed the questions under the leadership of the moderator, and at the end of the sessions each moderator presented the aspects highlighted by his/her group and the members elaborated if clarification was considered necessary. The data were collected in the form of notes by moderators, which means that the notes represent what the teachers as a group stated rather than their exact ways of expressing themselves. This also extends to the excerpts appearing in the study findings; they have been taken from the notes of the moderators as a representation of a group rather than being an individual statement.

\section{Data analyses}

In order to establish descriptive categories, the different understandings within and between groups were thematically analyzed. Thematic analysis is a method for identifying, analysing and reporting patterns (themes) within data. It minimally organizes and describes the data set in rich detail, and may even interpret aspects of the phenomenon (Braun and Clarke 2006:79, Boyatzis 1998). The themes identified are strongly linked to the data themselves and the 'keyness' of a theme is not necessarily dependent on quantifiable measures but rather on whether it captures something important in relation to the overall research question (Braun and Clarke 2006:82). These attributes encourage the employment of thematic analysis in this study. The analysis was conducted following the various phases of familiarization with data, generating initial codes, searching for themes, reviewing themes, defining and naming, and producing the report, as recommended by Braun and Clarke (2006).

Familiarisation with the content and understanding the data started during their collection and continued during analysis. While searching for meanings and patterns, a list of ideas about what is in the data and what is interesting about them was produced. Using the interesting data extracts, a list of different codes was later generated and actual data extracts coded were then collated together within each code. Through compilation and reduction, an organized version of a few sorted data-based themes was constructed. Here, multiple groupings of codes based on their meaning were made, and all the relevant coded data extracts were then collated within the agreed potential themes; thus ensuring that the extracts fitted into their themes and the proposed themes actually captured the contours of the coded data. By understanding the relationship between codes forming a theme, and the difference between the constructed themes, defining and naming the themes was possible. Attention was paid to names identified, being careful 
about the language to ensure that the names were concise and immediately gave the reader the sense of what the name was about. Through negotiated consensus, the final meaning and themes' names of, Dependence, Physical and economic resources, Experience of a deep approach to learning, Reading culture, and Previous preparation for higher education were arrived at. Finally, the text clearly explaining what the five potential thematic themes are about in relation to important problems when it comes to students' learning and the ways they approach learning is given below. Sufficient number of extracts demonstrating the prevalence of the theme have been provided.

\section{Findings}

This section presents the findings from the analyses and their detailed discussion in relation to previous studies. The findings build on the following question posed to the participants: What are the most important problems when it comes to students' learning and the way they approach learning? In the empirical data, a fairly large number of aspects were raised by the participants. The table below lists the main themes identified to provide an organizing framework prior to presenting the detailed findings. Each section begins with a brief description of the meaning of each theme, followed by excerpts from the interview chosen to provide both a "flavour" of evidence, on which the summaries are based, and an expansion and clarification of the distinctions being made, and ends with detailed discussion in connection with what the theories have to say so that a deep understanding and interpretation is ensured. The excerpts are taken from the notes of the moderators, and thus represent a summary of what the teachers in a group stated, rather than their exact ways of phrasing themselves. The letter $\mathrm{G}$ followed by a number identifies the group from which the excerpt is taken.

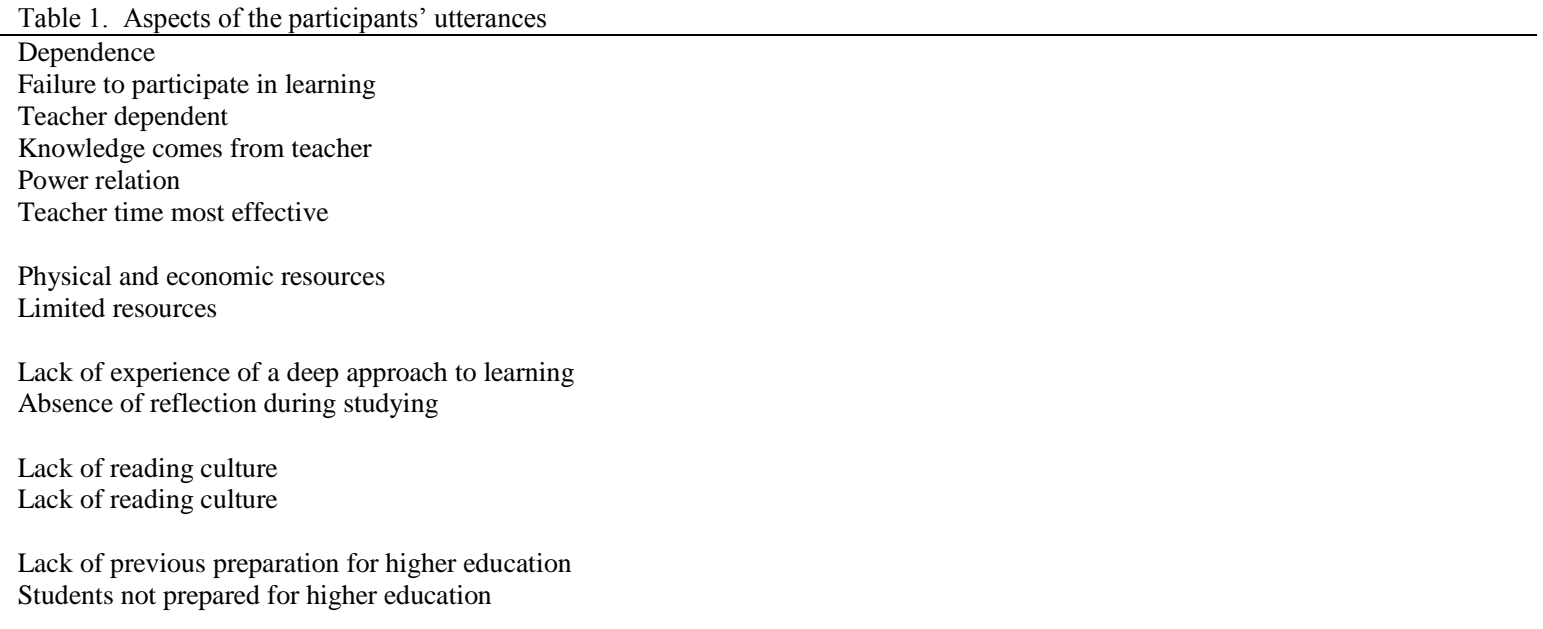

\section{Dependence}

The issue of students' dependence on teachers, seen as a problem to students' learning and the ways in which they approach learning was one of the themes that emerged in the analysis. Below, are excerpts from teachers on the issue of dependency,

Students' failure to participate in learning; the students expect the teacher to study and then bring the knowledge to them. (G1, G2, G3, G5)

Students are dependent on teacher, students think that all the knowledge comes from the teachers, and the time spent on learning is waste of time (G1).

During teaching and learning, the teacher's time is most effective (G1, G2, G5). 
Students feel that a teacher is a power and should not be questioned; this makes students see themselves in a receiver's position where they expect to receive everything from their teachers (G3, G5).

Outside class, no contact with lecturers and students feel abandoned and believe no study can take place without him/her. This, in turn gives lecturers so much power as they continue to spoon-feed the students and hold them to ransom through tests, examinations and other forms of formal assessment (GI).

By analyzing these teachers' excerpts about dependency, the following aspects are discerned: reliance, sufficiency, students' involvement and commitment unnecessary, and power relation. Here, the implication is that the teacher is regarded as the guardian of knowledge if not its conveyor. Is this attributable to learning experience?

In the third excerpt above, the explanation given is that most of the time is utilized by the teacher and that the teacher's time is more effective compared to the student's time. The explanation by the teachers signals an element of interaction where both teacher and student are involved in learning, on the one hand, and an implication of less involvement and input from students on the other.

There is also an aspect of power relations that is stressed; students might feel that they are not free with their teachers. There is an argument that students view their teachers as a power and as unchallengeable and this in turn gives teachers so much power that learning can not take place without them. If one critically considers the teachers' comments, one can discern an aspect of ineffective networking between students and teachers and this is linked to the students' background. Historically, students have learnt throughout their educational career that a teacher is an unchallengeable, inaccessible, unfamiliar person who has all the power to determine their future. Students have taken with them this kind of conception into higher education and still portray it in their interaction with their teachers. This could be an obstacle to effective learning in the sense that it blocks the opportunity to access feedback about teaching and learning. As expressed in the notes from Group 2: 'A good teacher-student relationship should promote effective communication and free sharing of knowledge and experience so that both can have a common view of understanding as far as teaching and learning are concerned.'

What we see here is that students are not encouraged to be independent in their learning but rather wait for the teachers' study materials. Bearing in mind that teaching and learning are intertwined, involving both teacher and student, one can identify two main factors, both teaching and learning approaches, supporting this kind of dependency in learning (knowledge transmission). Biggs (1996) suggests that for teachers to obtain the desired performance of understanding in their students, the different agents in the teaching and learning process (teachers and students) should engage in teaching/learning activities. Previous related studies by Bowden and Marton (1998) and by Ramsden (2003) have mentioned that aspects similar to those discerned above are characteristics of a surface approach to learning together with a teacher-centred approach to teaching. Furthermore, this happens to be in consonance with the acquisition metaphor for learning (Sfard 1998), which imagines learning as transmission, reception, attainment, internalisation, accumulation, etc., associated more with traditional learning. Warren (2004) describes surface learning as not promoting understanding or long-term retention of knowledge and information. Students' experience the relevance of learning extrinsically and the quality of their learning outcomes or capacity to handle tomorrow's situations is not a priority (Ramsden 2003). Available studies (Prosser and Trigwell 1999, Biggs 2001, Abrandt Dahlgren 2001) tell us that a teacher-centred approach encourages knowledge transmission, allows for more time and active involvement on the part of the teacher while there is less time and less involvement of students.

When students and teachers share the understanding of what it takes to learn, we would then expect improvements in the quality of learning in higher education. This might be possible if there exists a close teacher-student interaction and hence effective communication. By keeping an active watching and 
listening to their students, teachers can be in a good position to know both the strong and weak points in teaching and learning, which will consequently enable the teacher to know where, what, how and when to improve the situation for better outcomes.

The more students fear their teachers, the more the gap widens, with the likelihood that the students' attitude and interest in learning subject will be affected. Indeed, previous studies have suggested that attitudes towards learning and teaching are more important than methods and techniques. One might conclude that as long as the culture of interaction is not well developed, even the interaction between students themselves is affected in the sense that discussions about studies among students are both minimal and non-productive.

At this point, it is worth concluding that effective communication makes possible for teachers and students to access, understand, and support each other. Further effective communication creates an interest in and positive attitude towards learning and breaching of borders in learning benefits students based on a combination of individual and collective learning, which has a more positive influence on the quality of learning outcomes.

\section{Physical and economic resources}

The participants also raised other issues associated with resources as one of the problems behind students' learning. Some of their typical excerpts are:

We have limited facilities and resources, yet the new reforms require an improved study environment. The infrastructure is not adequate; there are too many students for existing classrooms, laboratories and even the libraries (G1, G2, G3, G4).

Students have to queue for the library materials, have little time to use the materials and have them returned to the library for others to use (G1, G3, G5).

Enrolment is quite high yet the infrastructures available are not being improved in order to support the increased intake (G1, G4). The ever increasing number of students admitted to universities every year, has put a significant strain on existing infrastructure and staff (G3)

Teachers regard the environment as being unfavourable for quality learning and outcomes. When the participants were asked to explain more in detail how the economic resources become a problem, the explanation given is that 'the institution is finding itself with insufficient funds to meet the constant need for improving the study environment and study materials; with the poor reading culture students have, still they have to queue for library materials (G2)'. This could allow one to get an understanding to what extent the library supports the student learning. Furthermore, considering the documentary information, the NUR top management admits, published in newspapers:

The university has a critical need to build capacities of its staff, infrastructure, and managerial institutions. We are able to accommodate only a quarter of our students also in bad conditions (Kwibuka 2009).

Facilities at the main campus are overstretched, the student - teacher ratio is very high, and this makes the student-centered system of teaching and learning difficult (Ntayombya 2008).

More than 1,000 new students were enrolled by the university in various disciplines, joining over 8,000 others at different levels who were already experiencing the problem of accommodation (Kwibuka 2007).

Comparing the teachers' and the top management's views, one realizes that there is a common challenge of limited physical and economic resources facing the institution. 
The inadequacy of physical and economic resources is said by teachers to have an impact on the students' learning. The student-teacher ratio is high, meaning that following up students may be difficult for the teachers; facilities are inadequate in size and number, and as a result overstretched; yet all these are essential for a supportive learning environment. Considering that all these challenges have financial implications and have been existing from period to period, the institution finds itself with insufficient funds to adequately meet needs. Cheng and Ching (2007) illustrate how a supportive study environment has been linked to quality learning and emphasise that lack of facilities can be one explanation of students' low motivation and lack of commitment to learning. In their study of lifelong learning, Lekoko and Modise (2011) mention support provisions systems for learners, where they argues that the learner's success is attributable to the entire situation in which she/he learns/lives. Thus, one of the possible interpretations is that insufficient physical and economic resources are a threat to the quality of the learning environment and, by extension, a threat to the quality of learning outcomes. Indeed, such a situation could make the achievement of reform goals even less realisable.

Education quality is the natural result of achievement of quality resources and inputs for the institution. Procuring scarce resources for effective functioning and ensuring smooth and healthy internal processes and fruitful learning experiences are critical in order to achieve stated goals and produce high quality educational outcome (Cheng and Tam 1997:25).

Abrandt Dahlgren (2001) states that a more supportive educational environment encourages students to take on a deep approach to learning, whereby the student's role changes in terms of increased responsibilities for active commitment in his/her studies and learning, while a less supportive environment encourages students to take up a surface approach to learning. Having analysed the situation of how economic resources can be a possible constraint to a supportive learning environment and reviewed how this can be a barrier to students' engagement in learning, one would not hesitate to emphasise that students' conceptions of learning must be developed in parallel with the upgrading of physical resources, hence a budget should be allocated to students to build stronger commitments and obligations to their learning, to building renovation, and to facilitating modernization (Chen et al. 2007). According to the OECD (2007:28)

Development of integrated financial and academic strategies for institutions could enable them to be both academically and financially healthy and sustainable. Institutions of higher learning may not be solely academically or financially driven, but rather bring the two sets of cultures and requirements together, ensuring that the financial opportunities and risks arise primarily from the actions of the academic staff of the institution. It is no longer appropriate to assume that their future role and position in their respective market will be driven solely by academic aspirations.

\section{Experience of a deep approach to learning}

Lack of experience of a deep approach to learning by students and even by some teachers is highlighted. Participants' excerpts on deep approach to learning included:

Students have the problem of failing to put questions to themselves, in other words failing to make reflections in their learning $(\mathrm{G} 2, \mathrm{G} 3, \mathrm{G} 4, \mathrm{G} 5)$.

Students use the surface approach to learning; they think that studying means memorizing the teacher's study materials/notes and reproducing them during examinations (G3, G5).

Some teachers are not innovative; they use the same old approaches they learnt during their school time - methodology (G1, G5). 
Students' practice of deep learning means 'cramming' the notes especially for assessment purposes, and after getting a passing grade the notes have no further value for them $(\mathrm{G} 1, \mathrm{G} 2$, G3, G4, G5).

It can be noted that the quality of learning seems to be lower than teachers expect. Students are criticized for their tendency to memorize information as well as for lack of reflection in their learning. However, the implication in these comments is that students do not approach learning with higher-level aims. One may then wonder if such a situation is attributable to how students understand learning and knowledge, both in terms of their previous and current learning experiences. It is also interesting to note how some teachers self-reflexively position the role of the teacher as important in facilitating a deep approach to learning among the students. A call is made for innovative teaching, where new methods need to be used.

The participants' utterances portray the learning experience and the kind of conceptions of learning that students are held to have. Reflecting on views of previous studies, Marton and Säljö 1984, Bowden and Marton 1998, argue that learners' perceptions of a learning task, ways of acting spring from and reflect their past experiences of similar situations, and thus mirror differences in their preconceived ideas about learning, implying that there is a link between conceptions of learning and approaches to learning. A possible interpretation here is that the learning experiences that students may portray may not only be attributed to higher education but also be linked to their previous educational background. According to Woldetensea (2008), if access to education is not balanced with quality and proper quality assurance mechanisms are not in place early on in the school system, the influx of poorly prepared students to higher education will increase, contributing more and more to overall quality deterioration. Thus considerable attention should be paid to the quality focus besides to the quantitative effort to achieve long-term effectiveness. Relating this to this particular study, a significant impact on independent learning would be the adoption of deep and surface approaches to learning from an early age, and the awareness of when to apply one or the other might be a useful preparation for learning in higher education. Put differently, the educational levels are interdependent, and thus there is a need to introduce deep approaches to learning at lower levels of education for children to develop a more elaborate meaning of learning, what it takes to learn, to develop learning skills at an early stage and throughout higher education.

These issues are also linked to teachers' way of carrying out their teaching. Some of the teachers called for innovative methods in teaching in order to facilitate a deep approach to learning. A traditional teacher centred way of teaching has been prevalent in Rwandan education, not least in higher education, as illustrated by Mugisha (2010) in his study of geography students in higher education in Rwanda. He calls for student-active methods of assessment in order to facilitate a deep approach to learning among the students. It is clear that quality learning, which in the past was mostly defined in terms of the amount of information one has acquired and recorded in examination percentages ranging from $100 \%$ to $0 \%$, is now measured by the amount of learning that can take place in real life situations (Lekoko and Modise 2011). Encouraging students to reflect on their own thoughts and actions and have an open dialogue where both individual and collective learning is produced, and where the students are coached to see phenomena and situations in new ways is crucial to quality learning (Bowden and Marton 1998). According to Abrandt Dahlgren (2001), a relevant example here could be Problem Based Learning (PBL), a way of designing teaching for the purpose of promoting a deep approach to learning among the students, commonly associated with participation, reflection, critical thinking, generic skills, acquiring knowledge intrinsically, and confidence promotion among students. Further more, it is important that higher education should facilitate learners' understanding of learning as looking beyond what is taken for granted and not primarily learning an absolute truth. The participation learning metaphor heavily emphasizes aspects of reflective learning, reflective discourse as well as collective reflection that might enable learners to go beyond their individual thinking (Sfard 1998). One might also argue that higher education should encourage innovations that capture multiple reciprocal relationships across boundaries at different points in the process of knowledge capitalization for purposes of improving students' 
familiarity with real-life experiences, e.g. the triple helix strategy that builds the academia-industrygovernment relations aimed at stimulating full learning through sharing (Etzkowitz, 2002).

\section{Reading culture}

Another theme raised by the participants relating to students' learning-related problems and their approaches to learning is the lack of a reading culture. The following excerpts are relevant to this theme:

There is lack of reading culture among students, it looks like they have not been exposed to the culture of reading and this heavily affects most of them when it comes to higher education (G1, G2, G5).

Students are unmotivated to read extensively, yet this is a universally standard academic requirement for tertiary students; and they heavily depend on lecture/course notes as lifeblood for their academic survival $(\mathrm{G} 1, \mathrm{G} 3)$.

It is as if students are not aware that a reading culture exists, and when students are assigned some reading tasks, they instead see it as the teacher running away from his/her role and now students are assuming the teacher's responsibility (G1, G3, G5).

Examining the excerpts above, there is an implication that students lack experience of reading. They avoid reading not because they are not interested and hate reading but because they have not been exposed to the culture of reading in their daily life or studies. It seems that reading is a teacher's responsibility and the learning content should be presented to students by the teacher.

The participants associate the students' poor reading culture with their background, as teachers claim most of the students have not been engaged in extensive reading in their previous learning. It is like students at the university are still expecting their teacher to transfer the findings of his/her reading to them during lectures. On entering higher education, students have difficulties in their learning, especially when they are exposed to student-centred learning that requires students to be independent explorers and discoverers. According to Abrandt Dahlgren (2001), students need to be trained and encouraged to accept learning as their responsibility and learn to develop study strategies by themselves in collaboration with a teacher, who acts as a monitor and guide. In the case of this study, this implies that students need to become familiar with deep reading, through which they can be exposed to a variety of phenomena that illustrate various variations, and hence become able to expand their understanding and knowledge, and develop confidence and independence in learning. It is important to note from previous studies that teachers need to know how to engage students, in order to sustain their interest, and gradually replace the conception that reading is a 'teacher's responsibility' with it is 'my responsibility'. Marton and Säljö (1984) in their findings concerning students' approaches to learning, indicate that there is a close relation between learners' motives and the ways they go about learning. Lastly, as an observation, one could make a link between reading culture and other learning factors observed previously. For example, a supportive learning environment and exposure to early deep learning could be some of the influencing factors for developing a reading culture.

\section{Preparedness for higher education}

The issue of students' lack of preparation for higher education was raised by all the groups. Some examples:

Students are not prepared for higher education. They think learning means passing examinations and this is achieved by reproducing the teacher's notes (G5).

When students join universities and still cannot get orientation to learning in higher education, they at times develop bias for some programs, and students resort to changing from one study option to another, thinking that the alternative would be easier to study (G5). 
Students are either unprepared or underprepared before entering the tertiary level; they assume the same style of learning as in secondary school. They think they have to wait for the teacher to come to class to tell them what to do $(\mathrm{G} 2)$.

Perhaps this lack of preparedness for higher education is attributable both to students' private life and their previous learning. Students can only be exposed to and get experience of higher education from previous studies and from their homes, say from parents during discussions at the "kitchen table".

Students' unpreparedness for higher education proves to be a problem when it comes to students' learning and the ways they approach learning. There is an impression that students are not enlightened about learning in higher institutions; their background knowledge appears to be shallow and this creates difficulty for students' learning and understanding. Reflecting on related studies, Entwistle et al. (2000) argue that on entering higher education, students often expect the right answers to be provided by their teachers, which they can then learn and reproduce. The findings in this article indicate students' failure to acquire an orientation to higher learning, and how this could lead students to assume wrongly that e.g. changing from one study option to another might lead them to 'easy study options'. In such situations, it is more likely that students will experience the relevance of their courses extrinsically. However, participants argue that this is heavily attributable to students' background (shallow prior knowledge as well as lack of experience of how learning takes place in higher education). This appears to be in consonance with the views expressed in Hodgson's (1984) study, where she identified students' background knowledge and familiarity with the subject as one of the sources of influence as to whether students experience the relevance of their lectures as extrinsic or intrinsic.

\section{Discussion}

The focus of this study is on teachers' notions about the most important problems related to students' learning and the way students approach learning in higher education. The rationale for carrying out such a study is that teachers will reasonably approach students based on their assumptions of what kind of support they need for their learning. Ultimately, greater understanding of teachers' notions about students' learning will help promote the quality of their learning. The discussion starts with the identified five important problems related to students' learning and the way students approach their learning, which teachers find all a challenge when it comes to creating quality in learning among students in higher education in Rwanda.

One of the main findings was the dependence of students on their teachers' work for their learning. Students understand that the teachers' work is sufficient for their learning and so there is no need for them to go beyond classroom notes. Students input less into their learning, they believe their teachers know everything and are unchallengeable so learning cannot take place without their teachers. Teachers find such an understanding a problem especially when it comes to students' involvement in their learning activity, and they heavily attribute this to previous learning experience. The results showed that insufficient physical and economic resources could be a threat to the quality of the learning environment and thus impact on the quality of learning by students. Teachers regard the environment as being unsupportive for quality learning and outcomes, they attribute this to lack of sufficient funds by the institutions for creating a supportive learning environment; and as a consequence, teachers regard this as a problem affecting students' understanding and commitment to their learning. The learning environment is understood to cover such things as classrooms, laboratories, libraries, accommodation. In this study, an argument raised is that an institution needs to be financially healthy to be academically healthy. Lack of experience of a deep approach to learning is another important problem and this poses a threat to the quality of students' learning and outcomes of learning. Students are criticized for the tendency to memorize information as well as for lack of reflection in their learning. The results show that students have not been regularly exposed to situations that enhance a deep approach to learning and that this influences the meaning students construct for learning; this constructed meaning could influence the way 
they approach their learning, and eventually influence the quality of their learning outcome. Furthermore, lack of a reading culture is conceived by the teachers as a problem when it comes to student learning. On entering higher education, students experience difficulties when they are exposed to independent learning that requires to read in greater depth, yet students expect their teacher to do the reading and then transfer his/her findings to them in form of class notes. Lack of exposure to a reading culture is especially attributed to their previous learning experience at an early age. Finally, there is lack of previous preparation for higher education. Students are not prepared for higher education and understand learning as leading to passing examinations, which is achieved by reproducing the teacher's notes. Consequently, they face difficulties in learning and in developing their understanding mostly during their first year at university, and this sometimes leads students to experience the relevance of courses, lectures and learning extrinsically. However, the argument here is that students' previous experience of outside and inside school has not prepared them for learning in higher education.

In one way, we can see how these five problems are interrelated. Due to the history of education in Rwanda, the students' prior experience of education is a traditional one with teacher-centred approaches to learning. In this way, they have not been regularly exposed to situations that enhance a deep approach to learning. This might also be connected to the lack of a reading culture. Without extensive reading experience, it might be a challenge to adopt a deep approach to learning in a university environment where reading is an essential element at the same time as the physical and economic resources are scarce. These aspects, taken together, might create a situation where students are not really prepared for higher education. Another connection between these categories is that they all refer back to the students' previous experience of learning. Prior learning experience appears to be a common reflection and hence a connecting point with the categories; the learning background culture, whether home or school based, has a significant influence on students' preparedness for higher education.

In line with previous research, the study found that the learning environment is crucial to how learners conceive of learning and influences the approaches learners adopt to their learning and the quality of learning outcomes. If this is related to higher education in Rwanda, in order to have a supportive learning environment, and if the academic quality transformation is to be achieved efficiently and effectively, teaching and learning systems, resources and information, and the approaches taken by the people involved in the reform need to be upgraded in parallel. According to Prosser and Trigwell (1999), Abrandt Dahlgren (2001), Cheng and Ching (2007), Lekoko and Modise (2011), a supportive environment encourages a deep approach to learning and increases students' active commitment to their learning. Teacher-student interaction is another factor that influences the approaches to learning students may adopt in the sense that it influences the learners' interest, motives and attitudes toward learning. Since the teachers in higher education are making an effort to take into account the needs of the learners, effective teacher-student interaction (communication) could be one way to achieve a better understanding of students. In turn, this could be a starting point for creating the means to support quality learning, especially as teaching in H.L.Is tries to promote independent learning among students while encouraging students to take responsibility for their own learning.

By applying the approach adopted in this article, it has been possible to acquire knowledge of teachers' notions of important problems when it comes to students understanding learning and the approaches they adopt to learning, in Rwanda. This is helpful insofar as it provides a starting point for reflection on the challenges and possible solutions to the situation in Rwandan higher education. As Rwanda aims for a knowledge-based society and to compete in the global economy (MINEDUC-ESSP 2010), and as the teaching and learning in higher education focuses on achievement of the intended learning outcomes by learners while aiming for the appropriate quality that is internationally credible, like many countries, higher education is subject to increasing demands on quality assurance in teaching and learning (Biggs 2001). This study illustrates existing learning related problems among university students and how we can go about dealing with them in order to contribute to enhancement of quality of learning in higher education in Rwanda. This study identified features of traditional approaches to teaching and learning (that defined quality learning as the amount of information one has acquired and recorded in 
examination-productive learning, Lekoko and Modise 2011) in the education system and these have been linked with poor quality learning outcomes. Interestingly, the study has contributed ideas for enhancing approaches to teaching and learning in higher education in Rwanda.

Lastly, the results of this study points to the need to understand the interdependence of educational levels and the need to expose students to deep learning in their early education. Critical to our understanding is that educators have often taken these levels to be independent of one another. This study illustrates, on the contrary, how the levels seem to be interdependent; the output of one level feeds the next level; that is, students' exposure to the learning practices in their early education, develop into learning conceptions that learners carry with them to higher education and these conceptions influence their learning behaviour or approaches in higher education. Relating this to the reforms in higher education in Rwanda, for example, while the teaching and learning in H.L.Is shift from a teacher-centred approach to a studentcentred approach, it is equally important for also the early levels of education to make their teaching and learning methods student-centred. Possibly the quality transformation being encouraged in Rwanda higher education could yield more positive results if a quality foundation were laid at the early levels of education, especially in view of the fact that education levels impact on one another. Students should not be identified with a fixed approach to learning. Rather, everyone is capable of adopting different approaches from early childhood and onwards (Ramsden 2003), and this needs to be taken into account when planning and designing higher education in Rwanda.

\section{References}

Abrandt Dahlgren, M., Reid, A., Dahlgren, L. O. and Petocz, P. (2007), Learning for the professions: Lessons from linking international research projects. Higher Education, 6, 129-148.

Abrandt Dahlgren, M. (2001), Portraits of PBL: A Cross-Faculty Comparison of Students' Experiences. Linköping Studies in Education and Psychology. no 80.

Abrandt Dahlgren, M. \& Dahlgren L. O (2002), Portraits of PBL: students' experience of the characteristics of problem-based learning in physiotherapy, computer engineering and psychology. Instructional Science, 30, 111-127.

Biggs, J. B., (1996), Enhancing teachinh through Constructive Alignment. Higher Education, 32, 347367.

Biggs, J., (2001), The reflective institution: Assuring and enhancing the quality of teaching and learning. Higher education, 41, 221-238.

Bowden, J., and Marton, F., (1998), The University of Learning (London: Routledge)

Boyatzis, R. E., (1998), Transforming Qualitative Information. (London: SAGE Publications)

Braun, V., and Clarke, V., (2006), Using thematic analysis in psychology. Qualitative Research in Psychology, 3, 77-101.

Chen, C., Phyr, S., and Sok, K., (2007), Benchmarking potential factors leading to educational quality. Quality Assurance in Education, 15 (2), 128-148.

Cheng, Y. C., and Tam, W. M., (1997), Multi-models of quality in education. Quality Assurance in Education, 5, 1, 22-31.

Cheng, Y., and Ching, M., (2007), School-based management and paradigm shift in education: an empirical study. International journal of Education Management, 21, 6, 517-541

Dahlgren, L O., Fejes, A., Abrandt Dahlgren, M., and Trowald, N. (2009), Grading systems, features of assessment and students' approaches to learning. Teaching in Higher Education 14 (2), 185-194.

Entwistle, N., McCune, V., and Walker, P. (2001), Conceptions, styles and approaches within higher education: analytic abstractions and everyday experience. In Sternberg R. J. and Zhang L. F., (eds), Perspectives on thinking, learning and cognitive styles (Mahwah, NJ, Lawrence Erlbaum Associates) pp, 103-136.

Entwistle, N., Skinner, D., Entwistle, D., and Orr, S., (2000), Conceptions and beliefs about "good teaching": An integration of contrasting research areas. Higher Education Research \& Development, 19, 5-26.

Etzkowitz, H., (2002), The Triple Helix of University-Industry-Government: Implications for Policy and Evaluation. Institute for Studies in Education and Research. 
Hodgson, V., (1984), Learning from lectures. In Marton F., D. Hounsell D. \& Entwistle N. J (eds), The Experience of Learning. (Edinburgh: Scottish Academic Press), pp. 90-102.

Krueger, R. A., and Casey, M. A., (2000), Focus Group Interviews: A Practical Guide for Applied Research, $3^{\text {rd }}$ edn (Thousand Oaks: Sage).

Kwibuka, E., (2009), NUR seeks \$110m for five-year strategic plan. The New Times, Kigali, March 20. http://www.newtimes.co.rw/index.php? issue $=13840 \&$ article $=14340$.

Kwibuka, E., (2007), Accommodation problem hits NUR student. The New Times, Kigali. January 16. http://allafrica.com/stories/200701171255.html

Kwizera, C., (2010), Rwanda varsities to adopt modular system of teaching. The New Times, Kigali, June 29.

Kwizera, C., (2011), Rwanda-Quality Education: Varsity Boards Urged to Uphold Quality Education. The New Times, Kigali, May 30.

Lave, J., and Wenger, E., (1991), Situated learning: Legitimate peripheral participation (Cambridge University Press).

Lekoko, R., and Modise, O., (2011), An insight into an African perspective on lifelong learning: towards promoting functional compensatory programme. International Journal of Lifelong Education, 30, 1, 5-17.

Marton, F., and Säljö, R., (1976), "On Qualitative Differences in Learning — 1: Outcome and Process" British Journal of Educational Psychology, 46, 4-11.

Marton, F., and Säljö, R., (1984), Approaches to Learning. In Marton F., D. Hounsell D. \& Entwistle N. $\mathrm{J}$ (eds), The Experience of Learning. (Edinburgh: Scottish Academic Press), pp. 36-55.

Marton, F., (1988), Describing and improving learning. In Schmeck, R.R., (ed.), Learning Strategies and Learning Styles, (New York: Plenum), pp. 53-82.

Mashishi. M.K., and Rabin. C.E., (1999), A study of the approaches to learning, engagement with the learning context and conceptions of learning of a group of fourth year accounting students. Paper presented at the HERDSA Annual International Conference, Melbourne, 12 July 15, pp. $1-15$. http://www.herdsa.org.au/wp-content/uploads/conference/1999/pdf/mashishi.pdf.

Materu, P., (2007), Higher Education Quality Assurance in Sub-Saharan Africa: status, challenges and promising practices. World Bank Working Paper No. 124, The world Bank, Washington, D.C.

Mugisha, I., (2010) Assessment and study strategies: A study among Rwandan students in higher education, ( Linköping: Linköping Electronic Press).

National Council of Higher Education, (2007), Rwanda National Qualification framework. Kigali, MINEDUC, June 2007.

Ntayombya, S., (2008), Stopping Private Students Raises a Number of Questions. Artcle from The New Times, Kigali, Rwanda. December 3, issue No.13732. http://business.highbeam.com/437666/article-1G1-195231429

OECD (2007), "On the Edge: Securing a Sustainable Future for Higher Education", OECD Education working Papers, no, 7, oecd Publishing. doi: 10.1787/220180871707

Official Gazette of the Repubilc of Rwanda (OGRR), (2006), Law governing the National Council of Higher Education. Kigali, Rwanda (accessed 4April 2011).

Openjuru, G. L., (2011), Lifelong learning, lifelong education in higher institutions of learning in Eastern Africa: the case study of Makerere University institute of Adult and Continuing Education. International Journal of Lifelong Education, 30 (1), 55-69.

Patton, M. Q., (2002), Qualitative Research and Evaluation Methods, $3^{\text {rd }}$ edn (Thousand Oaks: Sage).

Prosser, M., and Trigwell, K., (1999), Understanding learning and teaching: experience in higher education, (Buckingham: SRHE \& Open University Press).

Ramsden, P., (2003), Learning to Teach in Higher Education, $2^{\text {nd }}$ edn (London: Routledge Falmer).

Rwanda Ministry of Education, (2008), Education Sector Strategic Plan 2008-2012. Kigali, MINEDUC. Rwanda Ministry of Education, (2010), Education Sector Strategic Plan 2010-2015. Kigali, MINEDUC. http://www.mineduc.gov.rw

Rwanda Ministry of Education (MINEDUC-HEC), (2007), Higher National Qualification framework and procedures for quality assurance. Kigali, MINEDUC. 
Rwanda Ministry of Education (MINEDUC-HEC), (2010), Hand book for Academic Quality Assurance and enhancement and the maintenance of standards in higher education. Kigali, MINEDUC.

Rodriguez, L., and Cano, F., (2006), The epistemological beliefs, learning approaches and study orchestrations of university students. Studies in Higher Education, 31(5), 617-636.

Rogoff, B., (1990), Apprenticeship in thinking: Cognitive development in social context, (Oxford, UK: University Press).

Sfard, A., (1998), On Two metaphors for Learning and the Dangers of Choosing Just One. Educational Researcher, 27 (2), 4-13.

Warren, H., (2004), Engineering Subject Centre Guide: Learning and Teaching Theory for Engineering Academics (Loughborough: HEA Engineering Subject Centre).

Woldetensea, Y., (2008), Steering African higher education towards achieving the millennium development goals: quality assurance focus. Paper presented at UNESCO Third International Conference on Quality Assurance in Higher Education in Africa. Dakar Senegal, 15 September, 17.

Wurzburg, G., (2005), Why economic and financial sustainability matter for lifelong learning. European Journal of Education, 40 (1), 60-91. 